\title{
NON-METALLIC BRUSH SEAL IN HEAVY DUTY GT UNITS, GE-MADE FRAME NO 7, MODEL EA
}

\author{
Steve Ingistov \\ BP/WCC/USA
}

\begin{abstract}
This Paper describes design, fabrication, installation and operational experience with non-metallic brush seals installed in all four GT Units, GE-made, Frame No 7, Model EA, presently operating at Watson Cogeneration Company, Carson, California, USA. First non-metallic brush seal was installed early 2002 and is currently in operation. Non-metallic brush seal serves in particular application to reduce the leakage of lubrication oil into the axial compressor suction. At the time of installation, it was the first application[1], to author's knowledge, where the non-metallic bristle brush seal was used in heavy duty industrial gas turbine. Non-metallic brush seal can be successfully used where the local temperatures and pressures allow their safe usage. Compressor bearing number one is close to its suction where the air temperatures are low enough to enable the usage of non-metallic bristles which in turn are the core of the brush seals.
\end{abstract}

\section{INTRODUCTION}

Fouling of the axial compressor is costly and any Operator/User of gas turbine units is on a daily basis faced with the challenge to maintain the compressor as clean as possible.
Typical axial compressor contains many rows of rotating and matching stationary blades. The fouling of Inlet Guide Vanes (IGV) and first several stages of compression is the most damaging and affects the aerodynamic performance of compressor. The fouling of IGV and first several stages of compression has a "snow ball" effect on aerodynamic performance of entire axial compressor. It is not unusual to surge entire compressor when its blades are heavily contaminated.

Journal bearing number one is next to the thrust bearing and the combination of these two require significant amount of lubricating oil. In addition, both journal and thrust bearing are in the vicinity of the compressor suction. Figure 2A from Appendix illustrates the proximity of the lubrication oil supply point to the compressor suction bell mouth. If the lubricating oil is allowed to entrain the compressor suction it will be atomized by the main air stream and the oil mist particles having negligent weight will tend to stick to the roughened and already dirtdeposited blade surface. Sub-micron particles of ambient dust and the moisture from atmosphere, combined with the moisture carried-over from the intake air evaporative cooler and from the fog generator, form a fine paste of dirt which sticks to the blades surfaces. Users frequently apply on-line cleaners which must be environmentally friendly but may not be effective in removing the oily deposits. 
In addition, some dirt deposits removed from IGV and several first stages of compression may re-deposit themselves on the later stages of compression. Redeposited dirt may then cake-up due to the temperature rise of the compressed air and then cannot be removed by either on or off line cleaning. Severe blade fouling of this kind can be removed by abrasive on-line cleaning. In extreme cases the entire compressor must be pulled out and handcleaned [2], [3].

\section{NOMENCLATURE}

$C$-degrees centigrade

$c_{p}$-specific heat, air $(\mathrm{J} / \mathrm{kg}-\mathrm{K})$

$D_{c}-1^{\text {st }}$ stage blade tip diameter, (m)

$D_{h}-1^{\text {st }}$ stage hub diameter, (m)

$K$-degrees Kelvin

$G$-mass flow, (kg/sec)

$p_{r}$-pressure ratio, absolute values

$r=\frac{D_{h}}{D_{c}}$, dimensionless

$\Delta T_{\text {stage }}$-average total temperature rise per stage, $(\mathrm{K})$

$\omega$-rotor angular velocity (radians/s)

\section{ACRONYMS}

$C L$-center line bolt, rotor, shaft

$E C$-evaporative cooler

$G T$-gas turbine unit

$I A$-intake air

$I G V$-intake guide vanes

$I S F$-index of compressor sensitivity to fouling

$M I$-major inspection

$O D$-outside diameter

$O E M$-original equipment manufacturer

WCC - Watson Cogeneration Company

\section{BLADE FOULING}

Designers and Users of GT Units are fully aware of continuous problem associated with fouling of axial compressor rotor and stator blades. Significant fouling is caused by depositing of sub-micron dirt particles on the blade surfaces and by entrainment of the fine moisture. This moisture originates from atmosphere. In WCC IA is cooled by an evaporative cooler working in tandem with a fog-generating system. Certain amount of water particles from EC and fine water spray from the fog are IA-carried into the compressor suction. In addition to the above, airatomized lubricating oil starts to deposit on the aero foils of IGV and on the first stages of compression. As a result a fine oily paste layer is formed rather quickly. This fine paste layer becomes caked in the later stages of compression as the temperature of compressed air grows. The caked paste of dirt deposits is virtually impossible to remove by even off-line compressor cleaning. In severe cases of blade fouling abrasive blade cleaning with nut shells, rice and pecan shells under GT full load is applicable.

In extreme case of compressor blades fouling an aerodynamic surge may be initiated due to the significant change of incidence angle when it reaches its critical value.

Numerous researchers investigated the mechanism of the blade fouling and some useful empirical equations were generated to predict the sensitivity to fouling of particular axial compressors being integral parts of GT Units.

Academic Tarabrin [5] introduced Index of Compressor Sensitivity to Fouling (ISF) which is defined as follows:

$$
I S F=\frac{G c_{p} \Delta T_{\text {stage }}}{\left(1-r^{2}\right) D_{c}^{3}} 10^{-6}
$$

Equation (1) indicates strong dependence on compressor geometry, especially on the $1^{\text {st }}$ stage rotor blade tip diameter $D_{c}$. It also shows ISF dependence on air temperature rise across the stage of compression.

Since the $1^{\text {st }}$ stage of compression, rotor and stator, is most exposed to fouling elements, carried by 
oncoming air stream via the bell-mouth, computation of ISF for the $1^{\text {st }}$ stage of compression is mandatory.

Substituting into equation (1) geometrical data for GE-built Frame No 7, model EA, axial compressor rotating stage No 1, ISF is computed equal to 1.74. This ISF can be classified as an average in comparison with other heavy duty, single shaft GT engines.

Table I compares GE-built Frame 7, model EA, GT with other GT models built by other OEM. Table I is based on Table I from [5].

Last column in Table I show GE-made Frame No 7, Model EA GT parameters and calculated ISF.

\section{Table I}

\section{Computed ISF for different GT models}

\begin{tabular}{|c|c|c|c|}
\hline $\begin{array}{c}\text { GT Model } \\
\text { OEM }\end{array}$ & $\begin{array}{c}\text { V94.2 } \\
\text { Siemens }\end{array}$ & $\begin{array}{c}\text { GTE-150 } \\
\text { LMZ }\end{array}$ & $\begin{array}{c}\text { MS7001EA } \\
\text { GE }\end{array}$ \\
\hline $\begin{array}{c}\text { ISO Output } \\
\text { MW }\end{array}$ & 150 & 150 & 85 \\
\hline $\begin{array}{c}\text { Air flow, } \\
\text { kg/sec }\end{array}$ & 500 & 630 & 278 \\
\hline $\begin{array}{c}\text { Pressure } \\
\text { ratio }\end{array}$ & $10.6: 1$ & $12.9: 1$ & $12.4: 1$ \\
\hline $\begin{array}{c}\text { Number of } \\
\text { stages }\end{array}$ & 16 & 15 & 17 \\
\hline $\begin{array}{c}\text { Hub-to-tip } \\
\text { ratio }\end{array}$ & 0.520 & 0.422 & 0.635 \\
\hline $\begin{array}{c}\text { Delta T } \\
\text { stage, K }\end{array}$ & 19.25 & 23.34 & 20.64 \\
\hline Tip OD ,m & 2.173 & 2.365 & 1.806 \\
\hline RPM & 3,000 & 3,000 & 3,600 \\
\hline ISF & 1.29 & 1.36 & 1.74 \\
\hline
\end{tabular}

Tabulated values of ISF show that for example ISF (V94.2) is similar to ISF (GTE-150) and that it differs from ISF (MS7001EA). This can be explained by the fact that first stage rotor blades in $50 \mathrm{~Hz}$ GT units are much larger than those in $60 \mathrm{~Hz}$ GT units. These ISF computations should be taken with certain amount of caution and only rigorous field performance testing under similar ambient conditions and identical air filtration may substantiate the calculated results.

Table I does not show, a typical aero derivative GT engine which is more sensitive to fouling than a heavy duty, frame type industrial GT unit.

The fouling of axial compressor is a complex process that is difficult to predict and generalize. The fouling starts with IGV, progresses via $1^{\text {st }}, 2^{\text {nd }}, 3^{\text {rd }}, 4^{\text {th }}$ and downstream stages up to $8^{\text {th }}$ stage of compression. The fouling of each early stage of compression has more impact on aerodynamic performance. Stadler [4] investigated behavior of multistage axial compressors when exposed to fouling elements in surrounding atmosphere. Stadler also monitored the compressor performance when cleaned on-line and when cleaned off-line. He concludes that rigorous, cleaning schedule must be implemented from the start of GT Unit operation when the compressor is new.

Figure 1 shows clean compressor performance, GTE150 LMZ[5]. The lines labeled as $\mathbf{a}, \mathbf{b}$ and $\mathbf{c}$, show performance degradation when the early stages of compression are contaminated with dirt.

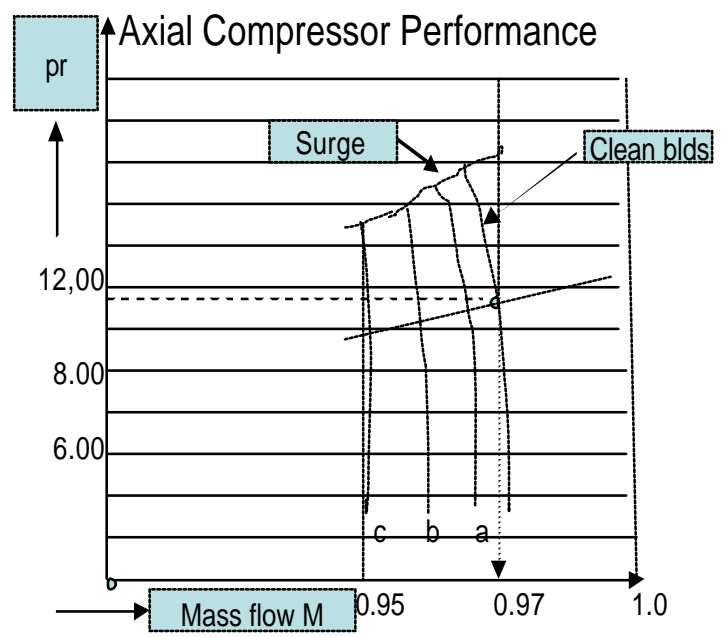

Figure 1 Axial compressor performance when the blades are clean (phantom line) and when the blades are fouled [5].

Phantom curve represents brand-new, clean compressor. 
Curve a shows fouled IGV and $1^{\text {st }}$ stage of compression.

Curve b represents fouled IGV plus $1^{\text {st }}$ stage of compression and second stage of compression, and so on.

Solid, straight, inclined line represents the line of compressor-turbine work.

Figure 1 also shows pressure ratio dropping from 11.50 (clean compressor) to 9.0, a case when all three stages of compression are dirty.

One may use these performance curves as a rough guide line for the other industrial GT Units.

The sensitivity of blade fouling (shown in Table I) varies from axial compressor to axial compressor. Various OEM provide blades which are more or less sensitive to ambient air fouling. Even the best intake air filters may not be able to arrest sub-micron dust particles and if the particular compressor blade geometry encourages the dirt depositing, such axial compressor is more sensitive to fouling.

\section{LUBRICATING OIL, PATHS OF FOULING}

The bearing housing No 1 contains journal and thrust bearings. The housing is horizontally split and furnished with $\mathrm{X}$ and $\mathrm{Y}$ Bentley Nevada-made noncontact vibrations probes. The end of the shaft, protruding from the bearing housing, is spinning inside the air-purged radial labyrinth. This labyrinth serves to minimize lubricating oil leakage into the suction of the axial compressor. The bearing No 1 housing is however surrounded by un-filtered air containing dust particles and various industrial fumes.

Figure 2 shows main path of this contaminated air leaking into the space formed by the intake air bellmouth and the rotor stub shaft-forward. This space is normally under vacuum conditions.

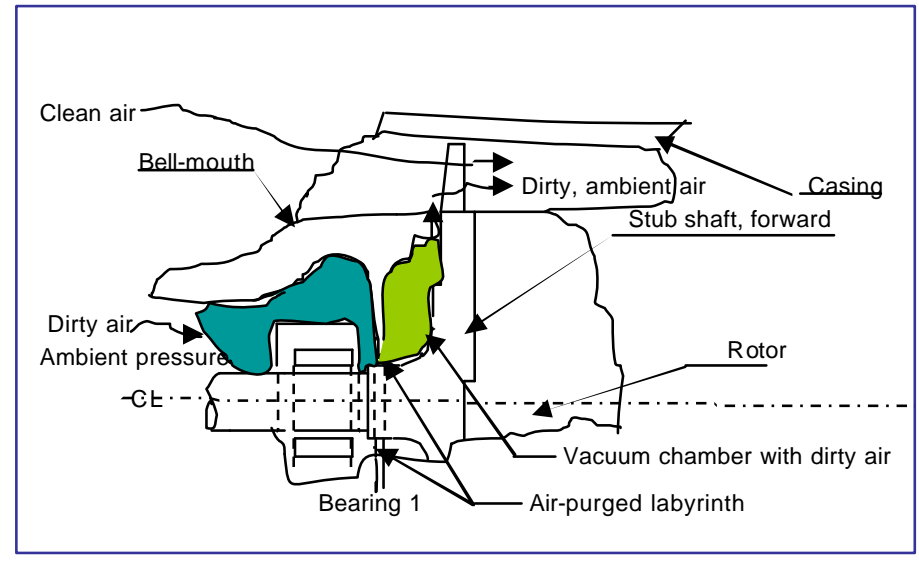

Figure 2 Infiltration of dirty ambient air into the "vacuum chamber" and compressed air path.

Air-purged labyrinth is shown just behind the bearing No 1. The purge air stream comes from $5^{\text {th }}$ stage of compression. Compressed air serves in this case as purge air only, in contrast to bearing No. 2 and bearing No 3 where the same purge air serves dual purpose:

- To prevent lubricating oil leakage, and

- To cool the bearing.

Bearings No 2 and No 3 are surrounded by an ambient of much higher temperature than the ambient surrounding bearing No 1 and therefore the purged air stream serves also to cool the bearing.

When the purge air is introduced into labyrinth seal downstream bearing No 1, the purge air temperature is higher than main air stream temperature. In addition, the purge air temperature is also higher than the lubricating oil temperature which is normally held to 120 degrees $\mathrm{F}$ at the supply point.

The following are the paths of lubricating oil leakage in the compressor suction:

- Along the bearing housing horizontal split

- Along the threads, B/N X\&Y probes

- Along the bell-mouth horizontal split, and

- Along the shaft air-purged labyrinth.

The bearing housing horizontal split must be flat and free of debris. Normally its surface is "stoned" and 
sealing compound such as silicon rubber No 102, or equivalent, is applied over the matching surfaces.

The threads cut in the upper half of the bearing housing to house Bentley-Nevada non-contact $\mathrm{X}$ and $\mathrm{Y}$ vibrations probes are sealed with thread sealing compound.

The bell-mouth casting, horizontally split, is very large in comparison with bearing No 1 housing and any leakage of dirty and oily air, coming from inside cavity of the bell mouth, will negatively affect the performance of axial compressor.

The most damaging path of leakage is along the shaft journal surface via air-purged labyrinth. The shaft journal, which is spinning at 60 revolutions per second, acts as a sort of inefficient pump, thus promoting oil leakage from bearing No 1 along the center line of the rotor. Leaked oil and dirty air enter the space formed by the compressor housing and matching part of the rotor. This space is under vacuum; 2-to-3 inches of water column.

This means that even air-purged labyrinth seal is not sufficient to retard the oil ingress into the compressor. The rational is then to augment the existing airpurged labyrinth with a brush seal gently contacting the high speed journal surface.

\section{NON-METALLIC BRUSH SEAL}

The very concept of having a non-metallic brush seal in GT Unit is un-orthodox, keeping in mind that all brush seals installed previously in gas turbines were metallic. The wiring of the brush seal bristles is made from special stainless steels, capable to survive hot and sometimes corrosive gases. The diameter of the wires and their density, per square inch, varies as required from application-to-application. To the author's knowledge the metallic brush seals were also used to replace carbon-made sealing rings on smallto-medium size steam turbines to prevent low pressure steam escape from the housing. In other words one could not find the brush seal manufacturer who had experience with non-metallic brush seals in GT application.
The application of non-metallic brush seal is realistic where ambient temperatures do not exceed $232 \mathrm{C}$. Bearing No 1 is surrounded by air that essentially is around $38 \mathrm{C}$ during the typical summer day, however the compressor intake air temperature seldom exceeds $18 \mathrm{C}$ due to IA cooling. The main concern is the compressor shaft journal metal temperature due to heat conduction effect.

The unknown, however is behavior of non-metallic bristles when in contact with lubricating oil. Another challenge is to make sure that oil, prevented from entraining the compressor suction, is constantly drained back to the lube oil reservoir. In case if it is not, then the bristles may start "swelling" due to socalled "wick effect". However, swollen bristles will further reduce oil leakage and, due to the oil "dam effect", friction of the non-metallic brush against the rotating journal will significantly grow. As the friction grows, the local temperatures will grow. Some of the lubricating oil will start to coke. The coked oil particles are abrasive and the shaft journal will see friction damage. Eventually, due to elevated friction-induced temperatures, the non-metallic bristles will start melting and significant amounts of lubricating oil may then enter the compressor suction.

It took WCC almost year and a half to find an Entity willing to build prototype non-metallic brush seal. Special attention was given to selection of material of the bristle. A nylon wire was selected to make first non-metallic brush seal. This type of nylon wire has good resistance to the "wick effect".

The holder of the brush seal was re-designed in order to maintain portion of the upstream labyrinth seal and also to hold the brush seal in the firm position. The brush seal was manufactured in two halves, each sliding into the "hook fit" cross section slot. Figure 3 shows the design concept of non-metallic brush seals.

There are two identical brush seals in tandem configuration in order to arrest as much as possible lubricating oil which is mixed with ambient air. 


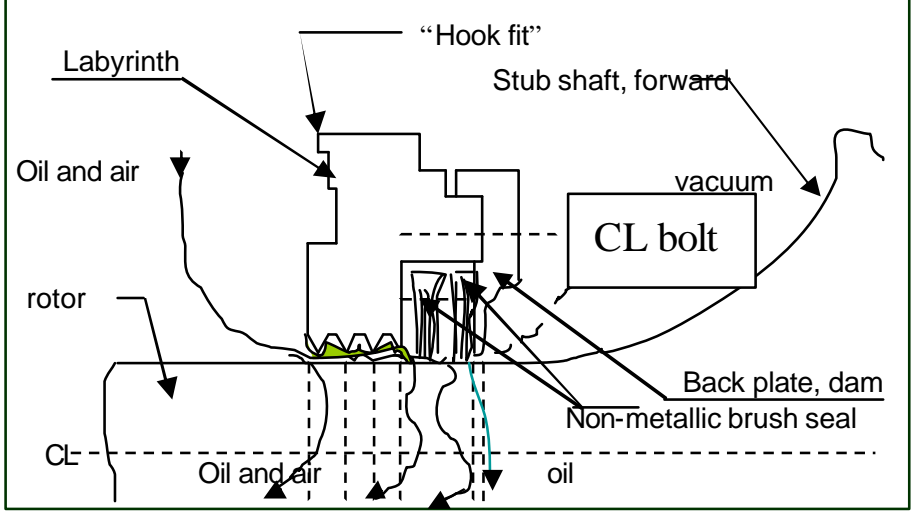

Figure 3 Standard labyrinth seal augmented by tandem non-metallic brush seals.

A brush seal-modified metallic labyrinth serves the following purposes:

- It is the first barrier to oily ambient air

- It drains accumulated oil, and

- It houses both non-metallic brush seals.

In order to further retard the leakage of oily air, the labyrinth teeth were also modified. Its "hook fit was replicated to fit into the existing compressor bellmouth casting.

The air purge from the $5^{\text {th }}$ stage of compression was retained in order to further slow down the leakage of oily air.

The last tooth of the labyrinth seal was provided with angle-drilled oil drain holes at the 6 o'clock position. If the drainage is inadequate, oil will form a dam and start flooding the bristles which may cause them to swell. In addition, the accumulated oil may start to coke up due to friction heat generated by brushes contacting the shaft. Carbon formation may further aggravate the performance of the brush seal and the stub shaft journal may suffer grooving damage due to a grinding effect.

A specially shaped back cover plate was designed to hold the non-metallic brush seal cartridge in the desired position.

\section{FIELD EXPERIENCE}

Each GT Unit in WCC is presently inspected for unusual fouling of the IA section, starting with the bell-mouth, IGV and first stage of compressor rotor.

In the past each compressor was found significantly fouled and first stages of compression were covered with oily deposits.

Numerous efforts to retard oil seepage into the compressor bell-mouth resulted in modest improvements.

First non-metallic brush seal was installed in 2002 and is still in operation. It was inspected after approximately three years of continuous operation and its bristles were found in satisfactory condition. The rotor area underneath the bristles was found slightly burnished.

Inspection of the lubricating oil reservoir revealed m bristles from the brush seal indicating good design and mechanical integrity of the first non-metallic brush seals.

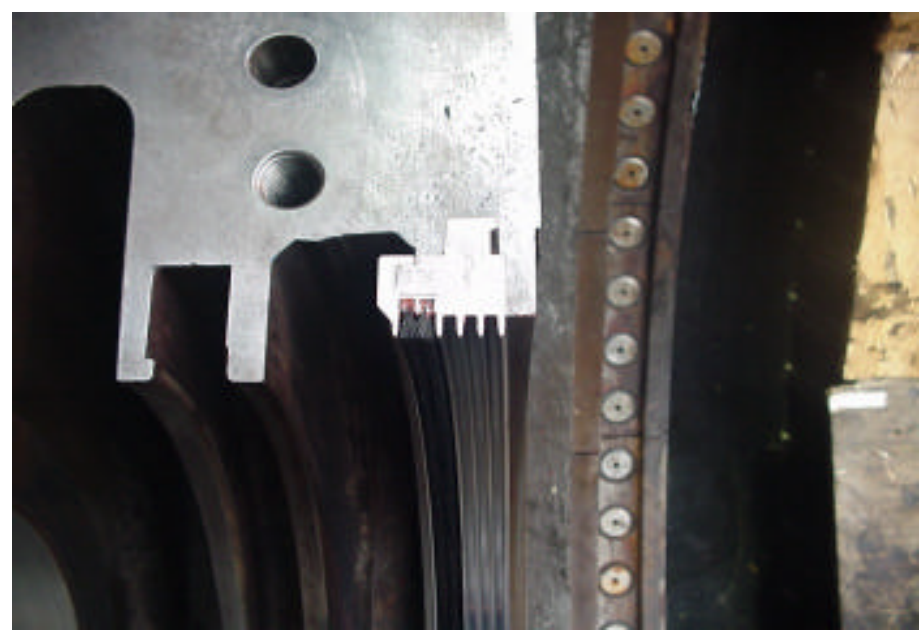

Figure 4 Bearing No1, lower half of labyrinth seal and non-metallic brush seal. Bristles are black colored.

The non-metallic bristles are of black color and are precisely cut to apply slight desired pre-load on the shaft journal. 
Figure 5 shows blue coating protecting the stub shaft forward from corrosion attacks. The particular brush seal was in operation slightly less than a year and yet one could not discern typical streaks of oil fouling on the stub shaft. However, the compressor blades were found to be significantly fouled, including obvious deposits of lubricating oil. Close examination of the possible leakage paths revealed some oil seepage along the horizontal bell-mouth split. It is noteworthy that even a relatively small amount of lubricating oil leakage can have a significant impact on axial compressor performance.

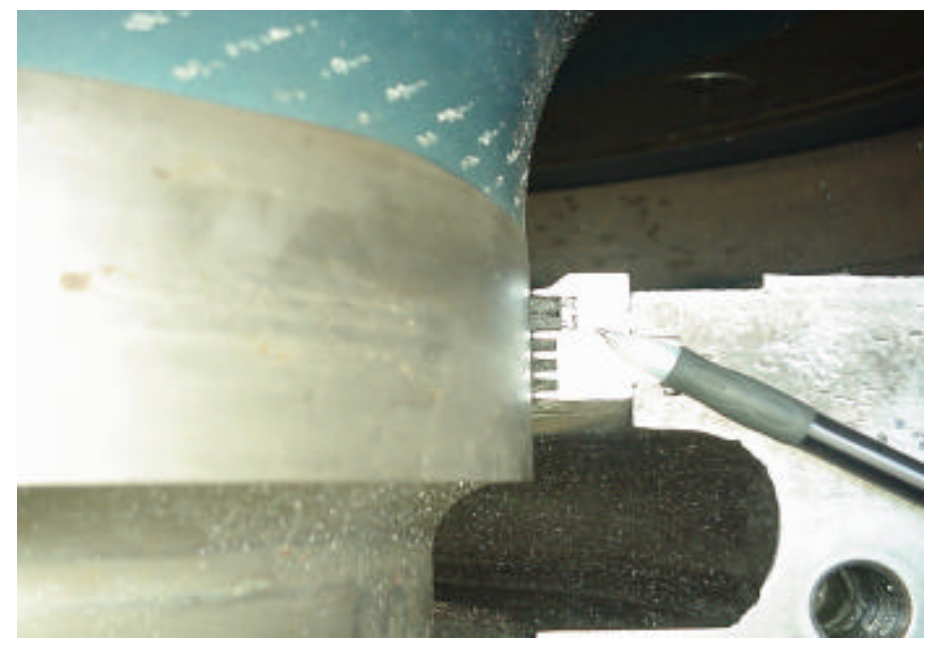

Figure 5 Brush seal contacting the journal of stub shaft forward. Blue coating is protecting the base material of the stub shaft forward.

Figure 6 shows brand-new non-metallic brush seal installed during March 2004 Major Inspection of GT Unit. The radius of the compressor rotor stub shaft forward is protected with corrosion-resistant coating of cream color.

Red color sealing compound (RTV) is used to prevent lubricating oil by-passing from horizontal splits of the bearing No 1 housing. Unfortunately, generous application of RTV actually separated the sealing surfaces encouraging the oil to leak. The use of nonmetallic bristles allows slight pre-loading in cold static condition. Examination of all four GT Units operating in WCC revealed only slight burnishing of the mating rotor cylindrical areas which were not protected with any kind of coating.

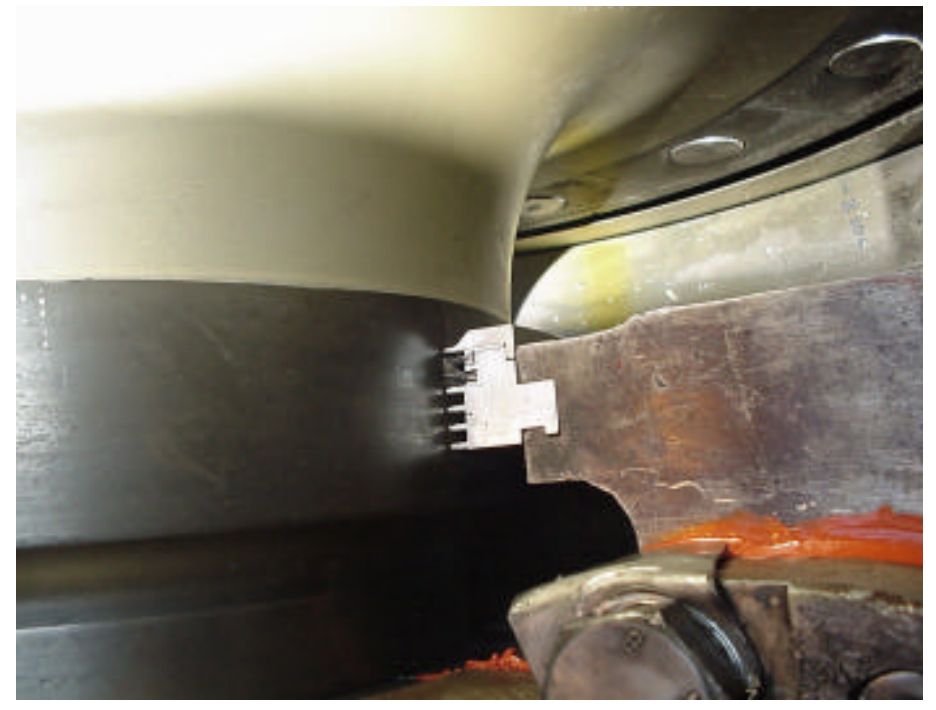

Figure 6 Brand-new non-metallic brush seal.

Figure 7 shows compressor rotor assembly just pulled out from the casing during October 2006 MI. First stage rotor blades were found seriously contaminated with dirt deposit. White streaks represent removal of dirt layer during on- line and off-line cleaning efforts. The stub shaft area is free of typical radial lubricating oil traces indicating good performance of nonmetallic brush seal. The fouling of the rotor blades is then due to the leakages of oil, dirty air and moisture via other paths of possible contamination already described.

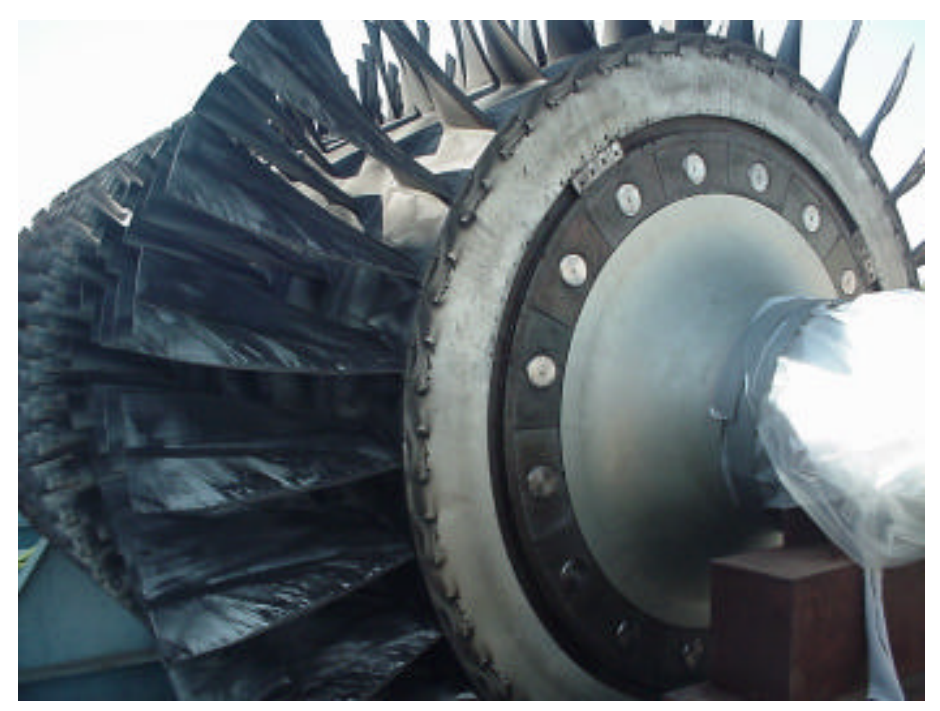

Figure 7 Contamination of the first stages of compression. Note the cleanness of the stub shaft. 
Solid performance of non-metallic brush seals, however aggravates the other paths of leak, such as for example, horizontal splits of the bell mouth and the bearing housing. In other words, more pressure is now applied on the weak links of the leakage path. Further efforts will be required to alleviate the lubrication oil leaks from other leakage sources.

\section{SUMMARY}

Non-metallic brush seal design, manufacture and field testing in WCC Power Cogeneration Plant is, to this author's knowledge, the first attempt in the GE-made Fleet of Frame No 7, Model EA, GT Units.

Field testing in WCC proved two very important characteristics of the particular non-metallic brush seals:

1. They are rugged and reliable, and

2. They minimize oil leaks along the stub shaft forward.

Proper provision for accumulated oil drainage, just upstream of the brush seal, is necessary to avoid the "flooding" of the shaft journal.

Selection of the material that the brush bristles are made from is crucial to avoid the "wick" effect and subsequent swelling of the bristles.

Understanding of critical parameters such as, for example, the vacuum level in the chamber just ahead of rotor R1 and the rotor journal temperature levels are important during the design and manufacture of non-metallic brush seals.

Further research efforts and laboratory testing are necessary to develop empirical equations predicting the oil seepage between the brush bristles.

Fouling of axial compressors is inevitable, however rigorous and disciplined on-line and off-line cleaning slows the inevitable, irreversible decay in aerodynamic performance.

An ounce of prevention is worth a pound of cure. Preventing the compressor blades from fouling, rather than sporadic removal of dirt deposits, is of paramount importance in maintaining GT Unit efficiency and reliability in production of power.

Academic Tarabrin's pioneering work in quantifying (ISF) and predicting the compressor blades fouling is of special importance for researcher, designer, fabricator and operator of industrial and aero derivative GT Units.

\section{ACKNOWLEDGEMENT}

Author wishes to express his gratitude to the People in WCC and also to WCC Manage ment for allowing this Paper to materialize and be published.

Special thanks to Garry Meredith, a $3^{\text {rd }}$ Party Representative who made the non-metallic brush seal work.

Thanks to Reviewers of this Paper for their corrections, comments and help.

\section{REFERENCES}

[1] Ingistov, S. "Method And Apparatus For Reducing Contamination In An Axial Compressor" US Patent No 6,609,888, August 26, 2003.

[2] Ingistov, S. "Axial Compressor Overhaul" GT 2005-68378, June 2005, Reno, NV, USA.

[3] Ingistov, S. "Axial Compressor Overhaul, Part II”, GT2006- 90698, June 2006, Barcelona, Spain.

[4] Stadler, J. P. “Compressor Washing Maintains Plant Performance and Reduces Cost of Engineering Production", 1994-GT-436, June 1994, The Hague, Netherlands.

[5] Tarabrin, A.P., Schurovsky, V.A., Bodrov, A. I., Stadler, J. P. "An Analysis Of Axial Compressor Fouling And Cleaning Method Of Their Blading", 1996-GT-363, Birmingham, UK. 


\section{APPENDIX}

Figure 1A shows simplified geometry of $1^{\text {st }}$ stage rotor blade. Diameters of the hub and the blade tip are instrumental to compute ISF.

Certain assumptions are taken such as the typical inlet air temperature at the bell mouth of the compressor, the magnitude of the vacuum that exists just before first stage rotor blades and the pressure ratio across the first stage of compression. It is also assumed that equal work of compression is done between the rotor and the stator blades, in other words the "reactivity" of the blades is about $50 \%$.

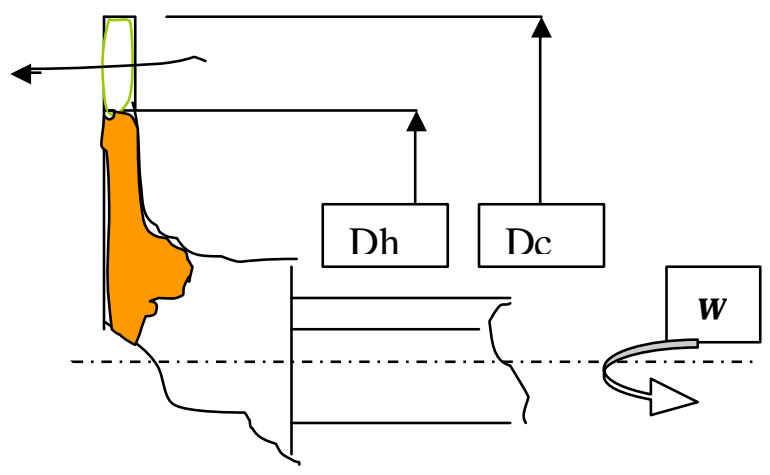

Figure 1A Dimensional parameters necessary to compute ISF.

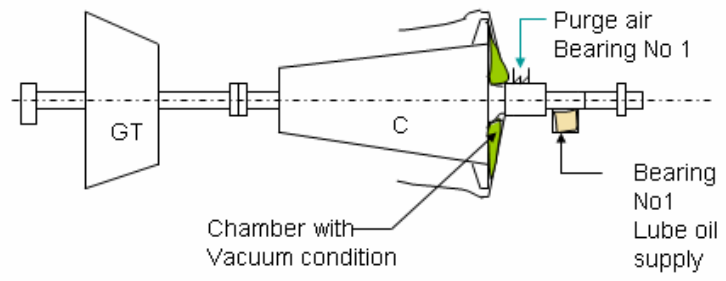

Figure 2A Turbine-compressor rotor showing the proximity of the journal bearing No 1 to compressor suction. 